\title{
Estimating the Earth's Outgoing Longwave Radiation Measured from a Moon-Based Platform
}

\author{
Hanlin Ye ${ }^{1, * \mathbb{D}}$, Huadong Guo ${ }^{2}$, Guang Liu ${ }^{2}$, Jinsong Ping ${ }^{3}$, Lu Zhang ${ }^{2}{ }^{\mathbb{D}}$ and Yiwen Zhang ${ }^{1}$ \\ 1 Qian Xuesen Laboratory of Space and Technology, China Academy of Space Technology, \\ Beijing 100094, China; 20161002795@cug.edu.cn \\ 2 Key Laboratory of Digital Earth Science, Aerospace Information Research Institute, Chinese Academy of \\ Sciences, Beijing 100094, China; hdguo@radi.ac.cn (H.G.); liuguang@radi.ac.cn (G.L.); \\ zhanglu@radi.ac.cn (L.Z.) \\ 3 Key Laboratory of Lunar and Planetary Exploration, National Astronomical Observatories, Chinese Academy \\ of Sciences, No.20 Datun Road, Chaoyang District, Beijing 100101, China; jsping@bao.ac.cn \\ * Correspondence: yehl@radi.ac.cn
}

check for updates

Citation: Ye, H.; Guo, H.; Liu, G.; Ping, J.; Zhang, L.; Zhang, Y.

Estimating the Earth's Outgoing Longwave Radiation Measured from a Moon-Based Platform. Remote Sens. 2021, 13, 2201. https://doi.org/ $10.3390 / \mathrm{rs} 13112201$

Academic Editor: Giancarlo Bellucci

Received: 19 April 2021

Accepted: 2 June 2021

Published: 4 June 2021

Publisher's Note: MDPI stays neutral with regard to jurisdictional claims in published maps and institutional affiliations.

Copyright: (c) 2021 by the authors. Licensee MDPI, Basel, Switzerland. This article is an open access article distributed under the terms and conditions of the Creative Commons Attribution (CC BY) license (https:// creativecommons.org/licenses/by/ $4.0 /)$.

\begin{abstract}
Moon-based Earth observations have attracted significant attention across many large-scale phenomena. As the only natural satellite of the Earth, and having a stable lunar surface as well as a particular orbit, Moon-based Earth observations allow the Earth to be viewed as a single point. Furthermore, in contrast with artificial satellites, the varied inclination of Moon-based observations can improve angular samplings of specific locations on Earth. However, the potential for estimating the global outgoing longwave radiation (OLR) from the Earth with such a platform has not yet been fully explored. To evaluate the possibility of calculating OLR using specific Earth observation geometry, we constructed a model to estimate Moon-based OLR measurements and investigated the potential of a Moon-based platform to acquire the necessary data to estimate global mean OLR. The primary method of our study is the discretization of the observational scope into various elements and the consequent integration of the OLR of all elements. Our results indicate that a Moon-based platform is suitable for global sampling related to the calculation of global mean OLR. By separating the geometric and anisotropic factors from the measurement calculations, we ensured that measured values include the effects of the Moon-based Earth observation geometry and the anisotropy of the scenes in the observational scope. Although our results indicate that higher measured values can be achieved if the platform is located near the center of the lunar disk, a maximum difference between locations of approximately $9 \times 10^{-4} \mathrm{~W} \mathrm{~m}^{-2}$ indicates that the effect of location is too small to remarkably improve observation performance of the platform. In conclusion, our analysis demonstrates that a Moon-based platform has the potential to provide continuous, adequate, and long-term data for estimating global mean OLR.
\end{abstract}

Keywords: Moon-based platform; outgoing longwave radiation measurements; observation geometry; global samplings; site selection

\section{Introduction}

The Earth's outgoing longwave radiation (OLR) refers to the thermal radiation emitted by the Earth-atmosphere system, which is a critical component of the Earth's radiation budget [1-7]. Presently, OLR is predominantly measured at the top of the atmosphere (TOA) from space-borne platforms [8]. Owing to much research effort, space-borne platforms are able to measure OLR at TOA at high accuracy levels [9-11]. In the early days of observations, the Earth's radiation budget, including OLR, was measured by the Nimbus 6 and 7, equipped with both Narrow Field of View (NFOV) and Wide Field of View (WFOV) instruments [12]. In the 1980s, the National Aeronautics and Space Administration (NASA) launched new generation Earth Radiation Budget Experiment (ERBE) instruments for measuring OLR [4,13], while, since 1997, the Clouds and the Earth's Radiant Energy 
System (CERES) provides OLR data for NASA's Earth Observation System (EOS) [10]. For a better understanding of the diurnal variation in OLR, the Geostationary Earth Radiation Budget (GERB) was developed to produce a global view every $15 \mathrm{~min}$, excluding all areas poleward of $72^{\circ}$ [14]. In addition, the Scanner for Radiation Budget (ScaRaB) project was also established to observe the Earth's radiation from polar orbiting satellites [15]. In China, OLR is one of the major observational parameters of the FengYun (FY)-3 series [16]. In 2015, the Deep Space Climate Observatory (DSCOVR) was launched by NASA, offering a new perspective for Earth observations $[17,18]$, and is located in a Lissajous orbit at the Sun-Earth L1 Lagrangian point, 1,500,000 km from the Earth. From this position, the platform has a continuous view of the Sun and the sunlit side of the Earth. The DSCOVR is equipped with two Earth-observing instruments, the National Institute of Standards and Technology Advanced Radiometer (NISTAR) and the Earth Polychromatic Imaging Camera (EPIC). The NISTAR views the Earth as one pixel and measures irradiance of the sunlit face of the Earth, while the EPIC takes images of the sunlit side of the Earth for various Earth sciences purposes. Notably, data acquired from the NISTAR can help quantify global OLR [19]. In recent years, microsatellites become the platform of observing the Earth's outgoing radiation. The Bolometric Oscillation Sensor (BOS), which is a broadband radiation instrument, is installed on the PICARD satellite and successfully launched in 2010 [20]. This satellite was placed at the dawn-dusk Syn-synchronous orbit [21]. Vertically aligned carbon nanotubes (VACNTs), which have an extremely flat spectral response over a wide wavelength range, onboard a $3 \mathrm{U}$ CubeSat measure the Earth's outgoing radiation and total solar irradiance [22]. Although the described observations have deepened our understanding of OLR distribution and variation, a number of limitations still exist in the estimation of global mean OLR [8,23]. For CERES, current OLR measurements for regional monthly uncertainties are approximately $5 \mathrm{~W} \mathrm{~m}^{-2}$ [24].

The global mean OLR refers to the integrated OLR of the entire planet, which is closely linked to global climate change. Within this context, primary sources of uncertainty stem from observation geometry and sensor calibration. In addition, the longevity of space-borne platforms is an important issue. Ideally, an accurate estimation of global mean OLR requires long-term, global-scale, omnidirectional observational data with absolute calibration accuracy [23]. Theoretically, from the perspective of observation geometry, a more precise global mean OLR can be calculated by increasing both the observational scope and the angular sampling of observed points.

In recent decades, various proposals for establishing a lunar base for Earth observations have been discussed [25-27]. A potential application of a lunar base is the development of a Moon-based Earth observation platform, representing an alternative platform for the measurement of OLR at TOA [28]. This raises the question of whether a Moon-based platform has the potential, in terms of observation geometry, to acquire the data needed to calculate global mean OLR and represents the aim of our study.

As the Earth's only natural satellite, the Moon's orbit differs from the low earth orbits (LEO) and geostationary earth orbits (GEO) of existing platforms. Furthermore, a number of unique characteristics distinguish Moon-based OLR measurement platforms from other Earth observation platforms. Firstly, the large Earth-Moon distance means that sensors installed on the lunar surface can observe the Earth as a single point. This feature not only provides images of the Earth at a hemispherical scale, but also facilitates integral measurements of emitted radiation by observational scope. Secondly, a Moonbased platform allows for continuous observations of the majority of observed points for a minimum of eight hours, and the continuous observation angles of observed points can be obtained by Moon-based observations [29]. The variance in lunar inclination relative to the Earth's equator allows for complete observations of all regions of the Earth, and, compared to fixed inclination observations, increases the diversity of observation angles of regions on Earth. Owing to the anisotropic characteristics of OLR, recording combinations of multiple observation angles allows for the recording of data from various directions, which is beneficial for calculating global mean radiation. Thirdly, the long life-cycle and 
stable orbit of the Moon enable the recording of long-term time-series Earth observation data. As the lunar surface has a large load capacity, several different types of sensors can be installed to collect various types of data. Of course, the installation of sensors on the lunar surface includes significant challenges, such as the large difference between day and night temperatures [30] and the presence of high-energy particles from the outer space [31]. However, as similar issues are also a reality for space-borne platforms, developed solutions can be applied to lunar platforms [32,33]. In the following lunar exploration project, key technologies concerning the lunar base will be verified, and these issues will be solved in the future [25]. Based on these features, we used an active cavity radiometer to measure OLR emitted from the observational scope of a Moon-based platform as one pixel. Two primary channels were involved in acquiring OLR measurements, namely a shortwave channel $(0.2-5 \mu \mathrm{m})$ to measure reflected sunlight and a total channel $(0.2-100 \mu \mathrm{m})$. Total OLR is then be derived by subtracting the reflected sunlight from the total sunlight.

A number of studies have been conducted on Moon-based Earth observations. For example, in 1972, a far-ultraviolet camera was installed on the lunar surface during the Apollo 16 mission to observe the terrestrial atmosphere and geocorona. More recently, a new wave of lunar exploration has occurred with NASA organizing a Lunar Earth observatory workshop in 2007 to discuss the characteristics of Moon-based Earth observations [34,35]. In 2016, a special session was held at the International Geoscience and Remote Sensing Symposium (IGARSS 2016), where scientists from around the world discussed the research progress of Moon-based Earth observations [36-38]. Currently, the research on Moon-based Earth observations is primarily focused on the processing of existing observational data $[39,40]$, the investigation of Earth observation geometry [41-44], model simulations [45-47], and potential applications of Moon-based Earth observations [48,49]. Potential applications include the investigation of solid Earth tide using a Moon-based synthetic aperture radar (SAR) [49] and measurements of the Earth's radiation budget, as investigated in the present study. Within this context, Guo et al. [36] investigated the potential of a Moon-based platform to provide large-scale, continuously changing observation angles and long-term time series observations to improve the quality of data on the outgoing radiation of the Earth. Furthermore, Hamill [37] discussed the use of a particular instrument for recording observation of the Earth's atmosphere from the Moon, while Song et al. [50] analyzed terrestrial radiation observed and recorded from a Moon-based platform. Ye et al. [51] discussed the temporal sampling error of Earth's outgoing radiation viewed from a Moon-based platform, and Duan et al. [52] simulated terrestrial radiation at the entrance pupil of a Moon-based sensor. However, few studies have investigated whether the data collected by a Moon-based platform is suitable for estimating the global mean OLR using observation geometry, and there is a lack of theoretical analyses of the geometric characteristics required for measuring OLR using single-point observations. Therefore, in response, we developed a new model to estimate Moon-based OLR measurements.

In contrast to previous studies, we developed a theoretical model to identify the characteristics of Moon-based OLR measurements. From the developed model, we derived the observational scope and analyzed global samples. Furthermore, we identified the effects of observation geometry on the measurements, and based thereupon, estimated the differences in measurements recorded at different locations on the near side of the Moon. These differences can inform the site-selection for Moon-based platforms. Our study makes three contributions. The first contribution is the development of a theoretical model to estimate OLR measurements. In contrast to the methodology of [51,52], we separated the geometric factor from the expression of the measurement to reveal the effects of the observation geometry. Secondly, we derive an implicit expression for the observational scope allowing for the analysis of the characteristics of the observational scope to evaluate global samples of Moon-based Earth observations. Finally, we identify the distribution of OLR measurements from the near side of the Moon, examining the relationship between the OLR distribution and observation geometry. 


\section{Materials and Methods}

The goal of this study is to investigate Moon-based OLR measurements, which require Earth observation geometry, parameterization of the observational scope, and the anisotropic determination of OLR. Therefore, we developed a model to firstly, discretize the Earth into finite elements, and then, to integrate the calculations of the received OLR from all elements in the observational scope.

\subsection{Earth Observation Geometry}

To determine the geometric relationship between a Moon-based sensor and the Earth, we used Moon-based Earth observation geometry as the basis of the developed model, which requires the selection of a unified coordinate system. Moon-based Earth observation geometry primarily includes the location of the Moon-based sensor, the pointing vector of the sensors, and the points on the Earth. The position of the Moon-based sensor is initially given in the form of a selenographic coordinate system or Moon-centered Moon-fixed (MCMF) coordinate system, while the observed point is often given in the Earth-centered Earth-fixed (ECEF) coordinate system, requiring coordinate system transformations. Several studies have investigated the process of coordinate system transformations [36,49]. Commonly, the Jet Propulsion Laboratory Development Ephemeris (JPL DE) series are widely used data sources for acquiring lunar position and libration, as well as the position of the Earth. For the orientation of the Earth, Earth orientation parameters (EOPs) were used to obtain transformation matrices. For ease of calculations, the observation geometry is described in the ECEF coordinate system, with its origin at the Earth's barycenter and the $x$-axis points through the intersection of the Earth's equator and prime meridian in Greenwich (Figure 1). For the development of the model, a Moon-based sensor "S" was installed on the lunar surface with coordinates initially in the form of selenographic coordinates. Notably, the equator plane of the Moon is not parallel to the Earth's equator. For the measurement of OLR, to ensure that total OLR from the Earth, including the radiance along slant paths, can be measured by an Earth observation sensor, a reference level above the Earth's surface needed to be defined [53].

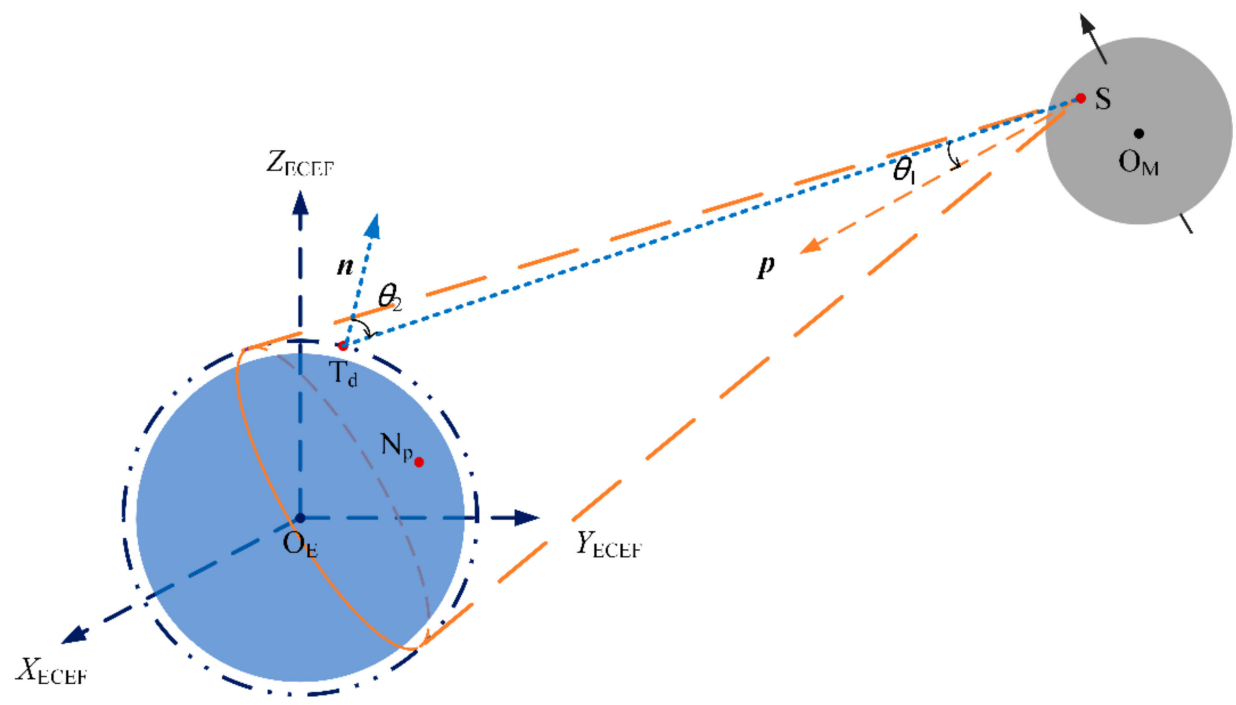

Figure 1. Illustration of the developed model's Moon-based Earth observation geometry including core geometric parameters. The origin of the Moon and the Earth are demarcated by $\mathrm{O}_{\mathrm{M}}$ and $\mathrm{O}_{\mathrm{E}}$, respectively, while $S$ refers to the Moon-based sensor. Point $T_{d}$, on the surface of the reference sphere (dash-dotted line) is a unit element within the observational scope, and vector $\boldsymbol{n}$ is its normal vector. The pointing vector, $p$, points through the Earth's barycenter, and the intersection point between vector $p$ and the reference level is denoted as nadir point $N_{p}$. By connecting points $T_{d}$ and $S$, the angle between $n$ and the line $\mathrm{ST}_{\mathrm{d}}$ is denoted as viewing zenith angle $\theta_{2}$, while the elevation angle $\varepsilon$ is the complement of the viewing zenith angle, and the angle between the $\boldsymbol{p}$ and $\mathrm{ST}_{\mathrm{d}}$ is denoted as $\theta_{1}$. 
For the developed Moon-based OLR measurement model, irradiance refers to the integral of the total irradiance in the observational scope received from a Moon-based sensor. However, as the observational scope is a spherical cap rather than a flat surface, different positions in the observational scope contribute differently to the integral OLR. In addition, neglecting the angle between the light ray and the pointing vector can lead to errors in the evaluation of the measured OLR. Therefore, two primary angles must be calculated - the first is the viewing zenith angle, which characterizes the direction of the unit element in the observational scope and can be utilized as a parameter of the anisotropic factor determination, while the second is the angle between the pointing vector and the light ray. Given the light ray $l$, the viewing zenith angle $\theta_{2}$ can be calculated as follows:

$$
\theta_{2}=\arccos \left(\frac{\boldsymbol{n} \cdot \boldsymbol{l}}{|\boldsymbol{n}||\boldsymbol{l}|}\right)
$$

This can also be calculated using the coordinates of the observed point $\left(\varphi_{d}, \theta_{d}\right)$ and the coordinates of the nadir point $\left(\varphi_{\mathrm{p}}, \theta_{\mathrm{p}}\right)$ as follows:

$$
\theta_{2}=\operatorname{arcos}\left(\sin \left(\theta_{\mathrm{d}}\right) \sin \left(\theta_{\mathrm{p}}\right)+\cos \left(\theta_{\mathrm{d}}\right) \cos \left(\theta_{\mathrm{p}}\right) \cos \left(\varphi_{\mathrm{p}}-\varphi_{\mathrm{d}}\right)\right.
$$

The angle between the pointing vector and the light ray can be calculated as:

$$
\theta_{1}=\arccos \left(\frac{p \cdot l}{|p||l|}\right)
$$

Assuming that the pointing vector points through the Earth's barycenter, the angle $\theta_{1}$ can also be expressed with the coordinates of the observed and nadir points as

$$
\theta_{1}=\arctan \left(\frac{\left.\cos \theta_{d} \sin \left(\varphi_{d}-\right] \varphi_{p}\right)+\sin \theta_{p} \sin \theta_{d}-\cos \theta_{d} \cos \theta_{p} \cos \left(\varphi_{d}-\varphi_{p}\right)}{\sin \theta_{p} \sin \theta_{d}+\cos \theta_{d} \cos \theta_{p} \cos \left(\varphi_{d}-\varphi_{p}\right)}\right)
$$

\subsection{Observational Scope Parameterization}

The observational scope refers to the portion of the Earth that can be observed by a Moon-based platform, with the purpose of calculating the relative position between the Moon-based platform and the coordinates of selected points on Earth. Notably, the sighting condition between the sensor and the target can be directly measured using the elevation angle. If the elevation angle is greater than or equal to $0^{\circ}$, the selected point can be observed using a Moon-based platform. The projection of the Moon-based platform on the surface of the equivalent reference Earth's sphere is called the nadir point. In Moon-based Earth observation geometry, the nadir point together with the observation distance, determines the boundary of the observational scope. Therefore, the calculation of the observational scope becomes the expression of the elevation angle as a function of the nadir point. In the following, the observational scope and its relationship to the nadir point are deduced.

Denoting the nadir point of the Moon-based sensor $\left(\varphi_{\mathrm{p}}, \theta_{\mathrm{p}}\right)$, the distance between the sensor and the nadir point $h_{\mathrm{p}}$, the Moon-based sensor in the ECEF coordinate system can be expressed as

$$
p_{\mathrm{ECEF}}=\left[\begin{array}{c}
\left(r_{\mathrm{TOA}}+h_{p}\right) \cos \varphi_{p} \cos \theta_{p} \\
\left(r_{\mathrm{TOA}}+h_{p}\right) \sin \varphi_{p} \cos \theta_{p} \\
\left(r_{\mathrm{TOA}}+h_{p}\right) \sin \theta_{p}
\end{array}\right]
$$

where $r_{\mathrm{TOA}}$ is the sum of the height of a reference level above the Earth's surface and the Earth's radius.

Similar to the expression of the case of the Moon-based sensor, given the coordinates of the observed point $\left(\varphi_{\mathrm{d}}, \theta_{\mathrm{d}}\right)$ and the altitude $h_{\mathrm{d}}$, the coordinates of the observed points can be written as:

$$
\boldsymbol{d}_{\mathrm{ECEF}}=\left[\begin{array}{c}
\left(r_{\mathrm{TOA}}+h_{d}\right) \cos \varphi_{d} \cos \theta_{d} \\
\left(r_{\mathrm{TOA}}+h_{d}\right) \sin \varphi_{d} \cos \theta_{d} \\
\left(r_{\mathrm{TOA}}+h_{d}\right) \sin \theta_{d}
\end{array}\right]
$$


Therefore, the line-of-sight vector can be expressed by the difference between the positions of the Moon-based sensor and the observed points, that is,

$$
\boldsymbol{l}_{\mathrm{ECEF}}=\boldsymbol{p}_{\mathrm{ECEF}}-\boldsymbol{d}_{\mathrm{ECEF}}
$$

Because the viewing zenith angle is defined in the topocentric coordinate system, while the line-of-sight vector is defined in the ECEF coordinate system, to express the viewing zenith angle, it is necessary to transform the line-of-sight vector to the topocentric coordinate system, which can be calculated as:

$$
\begin{gathered}
\boldsymbol{l}_{\mathrm{T}}=[\mathbf{R}] \boldsymbol{l}_{\mathrm{ECEF}} \\
=[\mathbf{R}] \boldsymbol{p}_{\mathrm{ECEF}}-[\mathbf{R}] \boldsymbol{d}_{\mathrm{ECEF}}
\end{gathered}
$$

The transformation matrix $[\mathbf{R}]$ is constructed as:

$$
[\mathbf{R}]=\left[\begin{array}{ccc}
-\sin \varphi_{d} & \cos \varphi_{d} & 0 \\
-\cos \varphi_{d} \sin \theta_{d} & -\sin ] \varphi_{d} \sin \theta_{d} & \cos \theta_{d} \\
\cos \varphi_{d} \cos \theta_{d} & \sin \varphi_{d} \cos \theta_{d} & \sin \theta_{d}
\end{array}\right]
$$

The line-of-sight vector in the topocentric coordinate system can be further written as:

$$
\boldsymbol{l}_{T}=\boldsymbol{p}_{T}-\boldsymbol{d}_{T}
$$

From the above equation,

$$
\begin{gathered}
\boldsymbol{p}_{T}=[\mathbf{R}] \boldsymbol{p}_{\mathrm{ECEF}}=\left[\begin{array}{c}
\left(r_{\mathrm{TOA}}+h_{p}\right) \sin \left(\varphi_{p}-\varphi_{d}\right) \cos \theta_{p} \\
\left(r_{\mathrm{TOA}}+h_{p}\right)\left[\cos \theta_{d} \sin \theta_{p}-\sin \theta_{d} \cos \theta_{p} \cos \left(\varphi_{p}-\varphi_{d}\right)\right] \\
\left(r_{\mathrm{TOA}}+h_{p}\right)\left[\sin \theta_{d} \sin \theta_{p}+\cos \theta_{d} \cos \theta_{p} \cos \left(\varphi_{p}-\varphi_{d}\right)\right]
\end{array}\right] \\
\boldsymbol{d}_{T}=[\mathbf{R}] \boldsymbol{d}_{\mathrm{ECEF}}=\left[\begin{array}{c}
0 \\
0 \\
r_{\mathrm{TOA}}+h_{d}
\end{array}\right]
\end{gathered}
$$

For the $\boldsymbol{l}_{\mathrm{T}}$, it can be expressed in another form:

$$
\boldsymbol{l}_{T}=\left[\begin{array}{c}
D \sin a \cos \varepsilon \\
D \cos a \cos \varepsilon \\
D \sin \varepsilon
\end{array}\right]
$$

where $\alpha, \varepsilon$, and $D$ represent the azimuth angle, elevation angle, and slant, respectively.

Combining the Equations (11)-(13), the elevation angle $\varepsilon$ can be expressed as follows:

$$
\sin \varepsilon=\frac{1}{D}\left[\left(r_{\mathrm{TOA}}+h_{p}\right)\left(\sin \theta_{p} \sin \theta_{d}+\cos \theta_{p} \cos \theta_{d} \cos \left(\varphi_{p}-\varphi_{d}\right)\right)-\left(r_{\mathrm{TOA}}+h_{d}\right)\right]
$$

To observe the points, $\varepsilon \geq 0$. Given the nadir point and the altitude of the Moon-based sensor, we obtain

$$
\sin \theta_{p} \sin \theta_{d}+\cos \theta_{p} \cos \theta_{d} \cos \left(\varphi_{p}-\varphi_{d}\right) \geq \frac{r_{\mathrm{TOA}}+h_{d}}{r_{\mathrm{TOA}}+h_{p}}
$$

\subsection{Anisotropic Considerations}

The general method of estimating Moon-based OLR measurements is to use the output of synthetic datasets. This output is usually in the form of irradiance, which includes radiation from all directions out to space. However, for Moon-based Earth observations, measured OLR equates to the integral of the radiance of each observed point in the observational scope emitted from a single observation angle. Because the Earth is a non-Lambertian body, to parameterize the observation angular anisotropy, the 
anisotropic factor can be defined as the ratio of the actual exiting radiance to the Lambertian exiting radiance.

As the anisotropy of OLR is a weak function of both the solar zenith and viewing azimuth angles, anisotropic factors are developed as a function of the viewing zenith angle and the latitude of the observed points [54-56]. In addition, as the anisotropic factor is subject to the Earth's scene and clouds at the observed points, information on these two aspects is a requirement. According to the definition of Suttles et al., [56], the anisotropic factor $X_{\mathrm{OLR}}$ can be calculated as follows:

$$
X_{\mathrm{OLR}}\left(\theta_{d}, \theta_{2}, \chi\right)=\frac{\pi I_{\mathrm{OLR}}\left(\theta_{d}, \varphi_{d}, \theta_{2}\right)}{F_{\mathrm{OLR}}\left(\theta_{d}, \varphi_{d}\right)}
$$

where $F_{\text {OLR }}$ is the irradiance derived from the datasets, $I_{\text {OLR }}$ is the actual exiting radiance, and $\chi$ refers to the scene type. The datasets herein refer to the numerical weather model data that can give out outgoing longwave flux in the form of grids. In practice, the anisotropic factors are tabulated by different scene types, viewing zenith angles, and latitudes. With these parameters, the anisotropic factor can be calculated.

\subsection{Estimation of the Moon-Based OLR Measurements}

The estimation of Moon-based OLR measurements requires a number of different steps (Figure 2). The first is to build Moon-based Earth observation geometry. The geometric relationship between a sensor and the Earth's position can be established through coordinate transformations. According to the observation principle, the measured OLR from a Moon-based sensor $F_{\mathrm{L}}$ at a latitude $\theta_{\mathrm{p}}$ and longitude $\varphi_{\mathrm{p}}$ of the nadir point within the observational scope can be expressed as

$$
F_{L}\left(\theta_{p}, \varphi_{p}\right)=\int_{\Omega\left(\theta_{d}, \varphi_{d}\right)} X_{\mathrm{OLR}}\left(\theta_{d}, \theta_{2}, \chi\right) \frac{F_{\mathrm{OLR}}\left(\theta_{d}, \varphi_{d}\right)}{\pi} \cos \theta_{1} \mathrm{~d} \Omega
$$

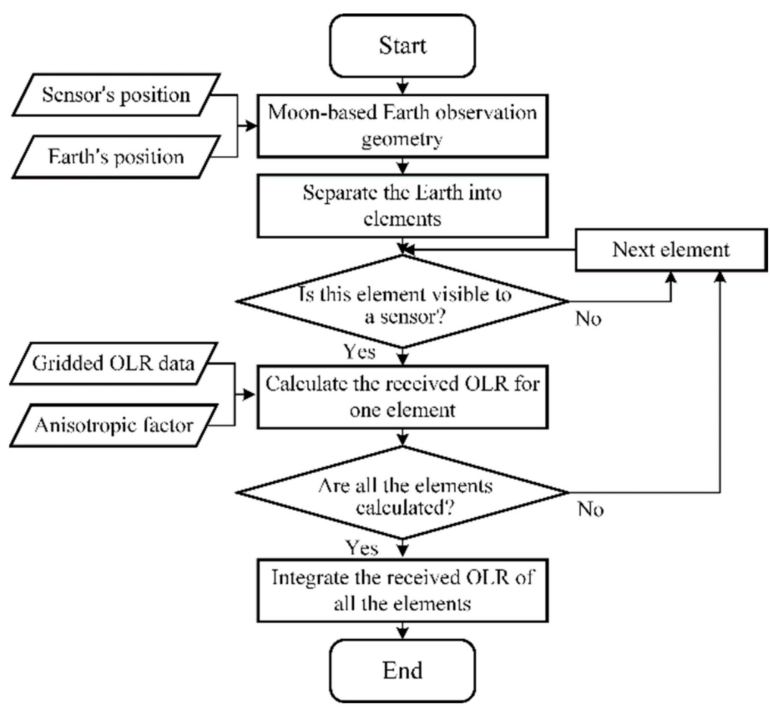

Figure 2. Diagram of the construction process of the theoretical model.

However, as it can be difficult to solve actual calculations, we separated the Earth into various elements. These synthetic datasets provide OLR measurements in the form of a given element's size. For convenience, the size of the elements was set to equal that of the prepared synthetic datasets. Subsequently, the elements need to be investigated as to whether they can be observed using Equation (15). If an element can be observed by a Moon-based sensor, the related received OLR of the sensor can be calculated. 
According to the radiation transfer theory, given the received irradiance OLR, $\Delta F_{\mathrm{L}}$ in the element with latitude $\theta_{\mathrm{d}}$ and longitude $\varphi_{\mathrm{d}}$, the expression can be written as:

$$
\Delta F_{L}\left(\theta_{d}, \varphi_{d}\right)=X_{\mathrm{OLR}}\left(\theta_{d}, \theta_{2}, \chi\right) \frac{F_{\mathrm{OLR}}\left(\theta_{d}, \varphi_{d}\right)}{\pi L_{i}^{2}} \cos \theta_{1} \cos \theta_{2} d s_{i}
$$

where $\mathrm{d} s_{i}$ is the area of the element and $L_{i}$ is the distance between the element and the sensor. By integrating all the elements in the observational scope, the Moon-based OLR measurement $F_{\mathrm{L}}\left(\theta_{\mathrm{p}}, \varphi_{\mathrm{p}}\right)$ can be derived.

To understand the effects of observation geometry on OLR measurements, further analysis is required. A feasible solution can be to separate the $F_{\mathrm{L}}\left(\theta_{\mathrm{p}}, \varphi_{\mathrm{p}}\right)$ into the separate contribution of each element in the observational scope. The irradiance of each element consists of the OLR derived from the data sets, geometric factors, and the anisotropic factor. According to the form of latitude-longitude grids, denoting the matrix of OLR from derived data set $[\mathbf{L}]\left(F_{\mathrm{OLR}}\right)$, geometric factor [G] (primarily consisting of $\theta_{1}, \theta_{2}, \mathrm{~d} s_{i}$, and $\left.L_{i}\right)$, and anisotropic factor $[\mathrm{A}]\left(\mathrm{X}_{\mathrm{OLR}}\right)$ of the same dimension, Moon-based OLR measurements can be written in the form of matrix $[\mathbf{M}]$, with the integral measurements equating to the sum of all the elements in $[\mathbf{M}]$. Thus, the expression can be rewritten as:

$$
\begin{gathered}
F_{\mathrm{L}}\left(\theta_{\mathrm{p}}, \varphi_{\mathrm{p}}\right) \quad \operatorname{sum}([\mathbf{M}]) \\
=\operatorname{sum}([\mathbf{A}] \circ[\mathbf{L}] \circ[\mathbf{G}])
\end{gathered}
$$

where $\circ$ is the Hadamard product.

Notably, the geometric factor [G] directly characterizes the observation geometry of Moon-based OLR measurements. These measurements and their relationship to observation geometry can be analyzed by comparing the differences in the observation geometry of the corresponding measurements.

\section{Results}

To estimate Moon-based OLR measurements, we developed a theoretical model and performed experiments to investigate the global sampling characteristics of a Moon-based platform and analyze the related measurements. Regarding our results, first, we introduce the characteristics of the observational scope and present the distribution of global samples during one orbital period. Second, we present the results from analyses of the characteristics of the geometric factors and their effects on the measurements. In addition, we report on the effects of different locations on the near-side of the Moon on the geometric factors. Finally, we present the distribution of the OLR measurements from different positions on the lunar surface.

\subsection{Analysis of Observational Scope Characteristics}

The orbit of the Moon has specific characteristics that affect the observational scope. According to the calculations used, the observational scope was determined by the orbit of the Moon, specifically the position of the nadir point and the observation distance. Within this context, we analyzed the characteristics of the observational scope using the observation distance and the position of the nadir point.

In order to reveal the regularity, we assumed the Moon-based platform was located at $\left(0^{\circ} \mathrm{N}, 0^{\circ} \mathrm{E}\right)$, and the grid size is set to $0.2^{\circ} \times 0.2^{\circ}$. Regarding observation distance, the Moon has an elliptical orbit, with the difference between the apogee and perigee approximately $40,000 \mathrm{~km}$. This indicates is a significant difference in the observational scope between the apogee and perigee. We investigated the distribution of the observational scope of a Moon-based sensor across different positions of the Moon, including (a) where the Moon moves around the apogee and (b) around the perigee during one orbital period (Figure 3a,b, respectively). Results from a comparison of the area of the observational scope between the two indicate that the observational scope at the apogee accounts for only $88 \%$ of that at the perigee. 


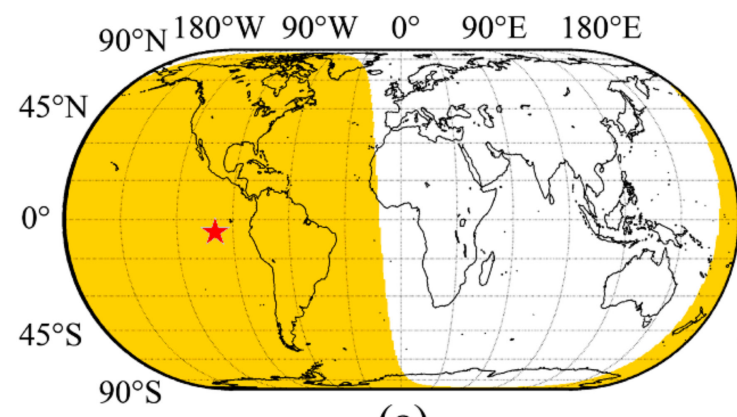

(a)

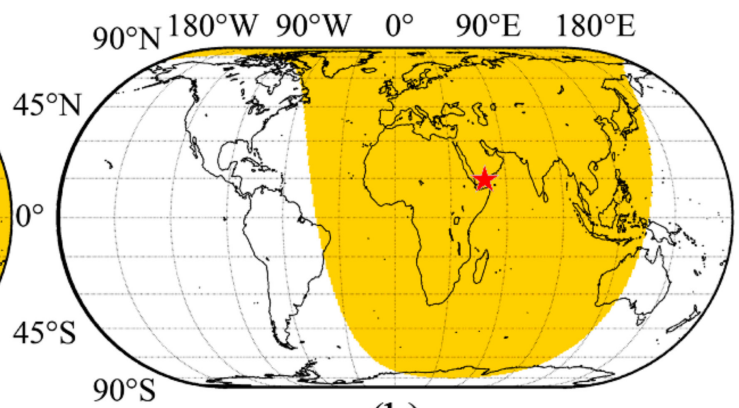

(b)

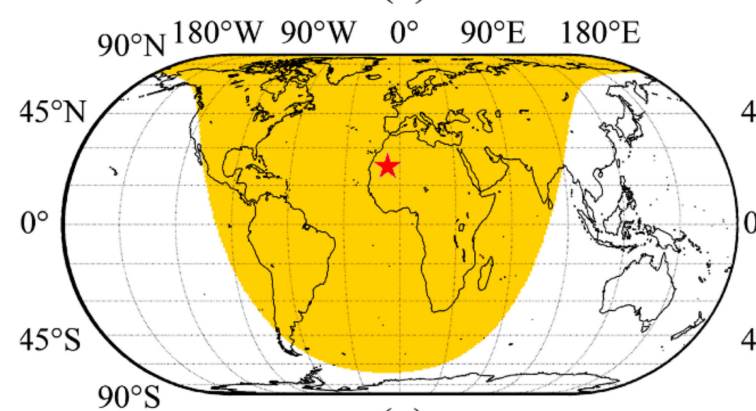

(c)

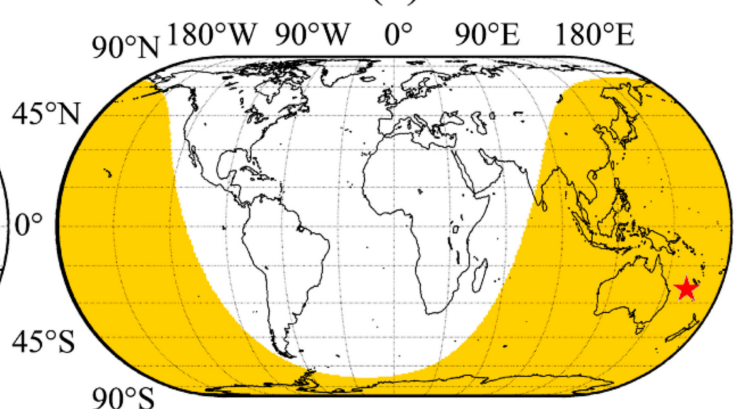

(d)

Figure 3. Observational scope of a Moon-based sensor when the Moon is at (a) perigee, (b) apogee, (c) maximum inclination above the Earth equator plane, and (d) maximum inclination below the Earth equator plane. The red dot is the nadir point of the Moon-based platform, which is the center of the observational scope.

For the position of the nadir point, the feature of the orbit of the Moon is the varied lunar inclination, which is embodied in the variation of the latitudinal range of the nadir point. Considering the inclination of the orbit of the Moon relative to the Earth's equator, the maximum inclination above or below the Earth's equator offers another two points of investigation (Figure 3c,d, respectively). It is clear that the area of the observational scope is only subjected to the observation distance, while the inclination determines the latitude of the nadir point and further affects the viewing zenith angle for the observed points in the observational scope. Under these circumstances, the polar regions can be observed, and the minimum viewing zenith angle of both the north and south poles can reach $62^{\circ}$.

Because the basic requirement of estimating the global mean OLR is global coverage, we further analyzed the characteristics and variation in the global samplings of Moonbased Earth observations (Figure 4). The unit is the number of samples, which is calculated by judging if the point is within the observational scope. We set the duration at both the orbital period of the maximum and minimum latitudinal range of the nadir point, to present extreme cases of global samplings during one orbital period. The interval for each sampling was set to $10 \mathrm{~min}$. It is clear that all regions on Earth can be fully sampled during one orbital period. The total number of samplings ranged from 1700 to 2100 . Both cases show uniform distribution along the Earth's latitude owing to the variation of the nadir point approximately along the latitude line. Based on this, we compared the samplings along the prime meridian (Figure 5). Owing to the varied lunar inclination, from the number of samplings the entire surface of the Earth can be divided into three parts, with two clear dividing lines determined by the maximum lunar inclination of the orbital period. In the region between these two lines, the samplings were more uniform, with their maximum differences are less than 100 times each. In the polar regions, different orbital periods exhibited different coverage levels, with the minimum number of samplings more than 1800, indicating adequate sampling of the polar regions from Moon-based Earth observations. 


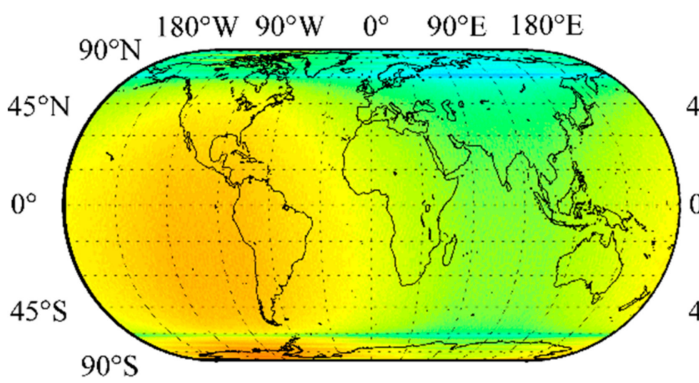

(a)

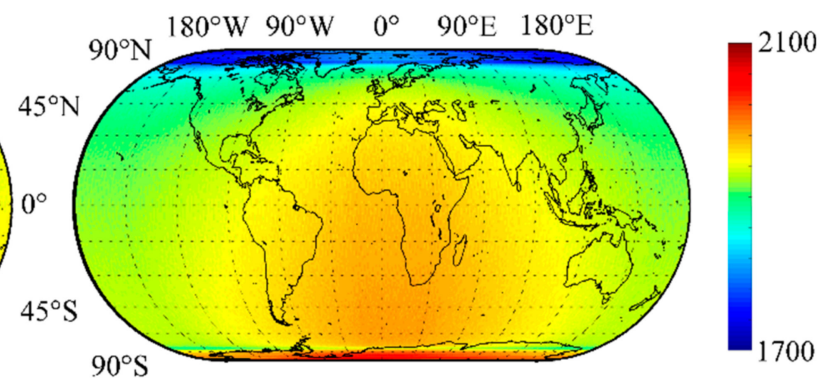

(b)

Figure 4. Distribution of the global sampling during the orbital period. The duration is set at the orbital period of (a) the maximum and (b) the minimum latitudinal range of the nadir point.

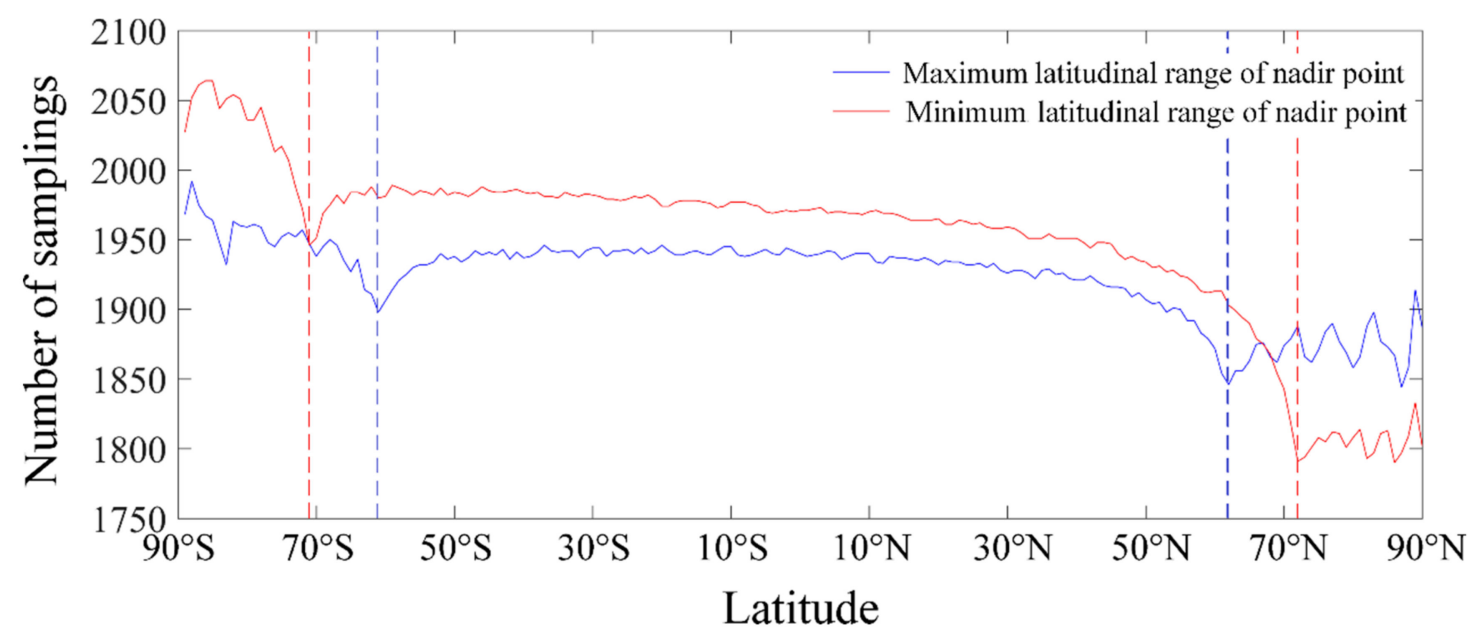

Figure 5. Number of samplings along the prime meridian during one orbital period.

\subsection{Moon-Based OLR Measurements}

Moon-based OLR measurements can be estimated using the output of numerical weather models. For our study, we selected simulation parameters of the OLR derived from the Goddard Earth Observing System Version 5 (GEOS-5). The GEOS-5 model records outgoing longwave flux in the form of grids, represented by $F_{\mathrm{OLR}}\left(\theta_{\mathrm{p}}, \varphi_{\mathrm{p}}\right)$ in Equation (17). The simulation began at 0:30 on 1 January 2016, through to 23:30 on 31 December 2019, with $1 \mathrm{~h}$ intervals. The FOV of the sensor is set to $2.1^{\circ}$. Although the simulated period only covered approximately five years, the characteristics of Moon-based OLR measurements can be clearly shown.

A time series of the Moon-based OLR measurements indicate a range from 0.058 to $0.083 \mathrm{~W} \mathrm{~m}^{-2}$ with a clearly cyclical pattern (Figure 6), caused by the component variation in the observational scope. As mentioned in Section 3.1, the position of the nadir point determines the observational scope. The time series approximately conformed to variations in the daily cycle, because the scenes observed by a Moon-based platform will change as the Earth rotates. As the diurnal cycles of land and oceans differ considerably [57,58], the changing portion of land and ocean will lead to changes in measured OLR. In addition, with changes in the nadir point, more high-latitude regions (northern or southern hemisphere) will appear in the observational scope. Thus, the time series also reflects orbital periodic and seasonal variations. 


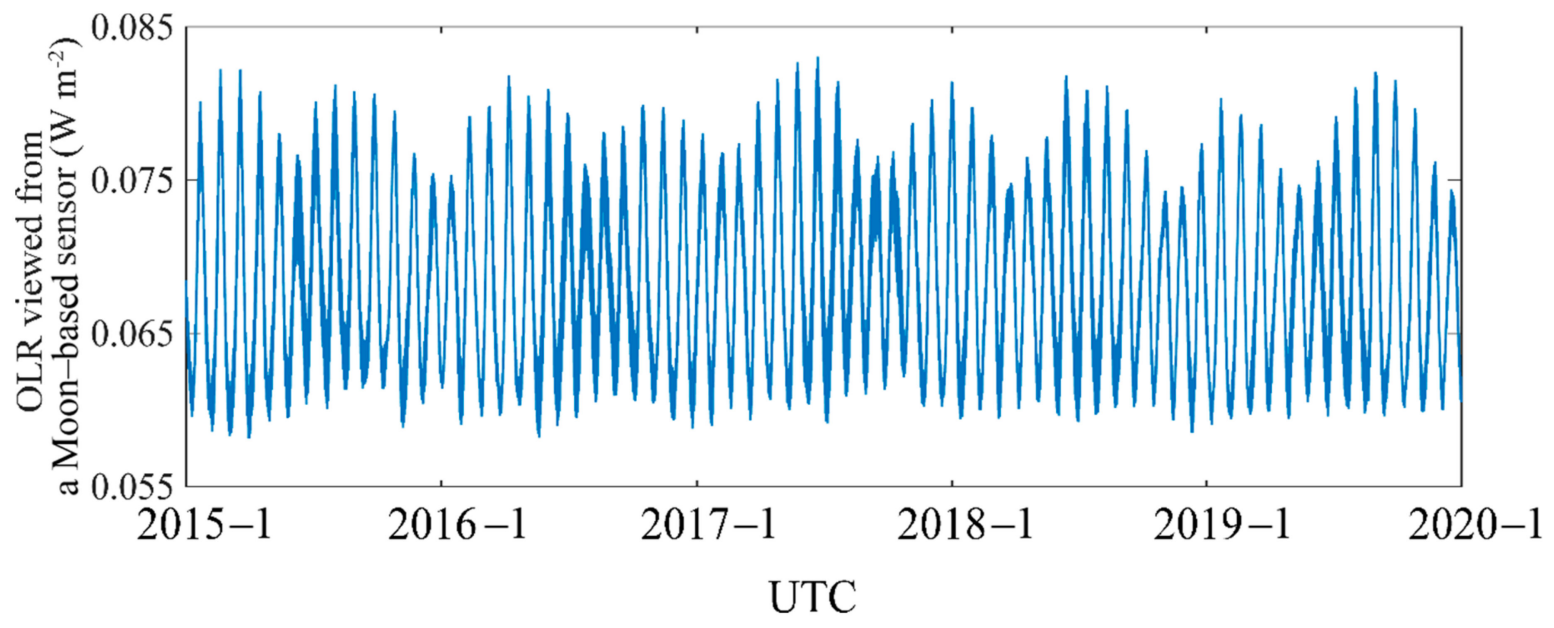

Figure 6. Variation of Moon-based outgoing long-wave radiation (OLR) measurements.

xSpecifically, the OLR depends chiefly on surface temperature and cloud cover (Figure 7a). It is evident that higher values occurred in the ocean and desert regions, which can be attributed to the warmer surface temperatures of these regions. Clouds also play an important role in the value of OLR by causing lower radiation at the TOA. The maximum OLR occurred over the sub-tropics with low cloud cover [59], while a local minimum was recorded near the equator, corresponding to cold temperatures at the cloud top [60]. To investigate the distribution of OLR in the observational scope (Figure $7 \mathrm{~b}$ ), values were normalized to amplify the contrast of the OLR at different positions within the observational scope. Owing to the effects of the Earth's curvature, it is clear that the values at locations near the nadir point contribute more to Moon-based OLR measurements generally, expect for regions where the emitted OLR is extremely low. In addition, the values decrease with an increase in distance to the nadir point. However, if the OLR at a particular position is too small, for example at Amazon Rain Forest, (Figure 7b), the contribution from this region will be far less than from other regions near the nadir point. The contributions of the OLR at different positions to the integral measurements were determined using the OLR values and the relative position to the nadir point.

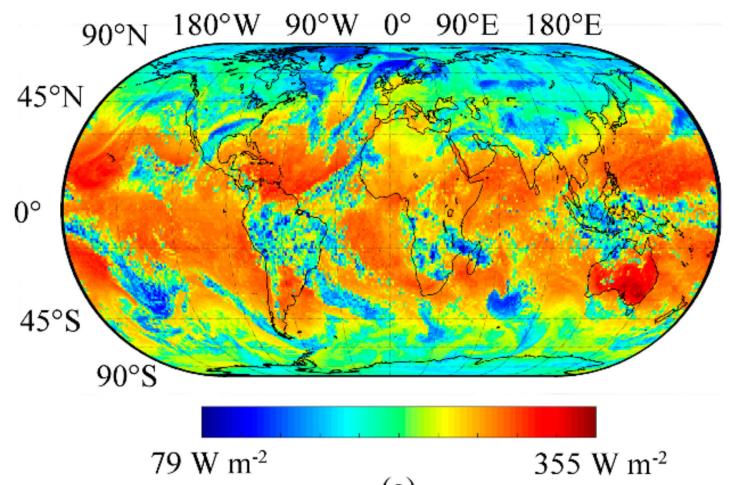

(a)

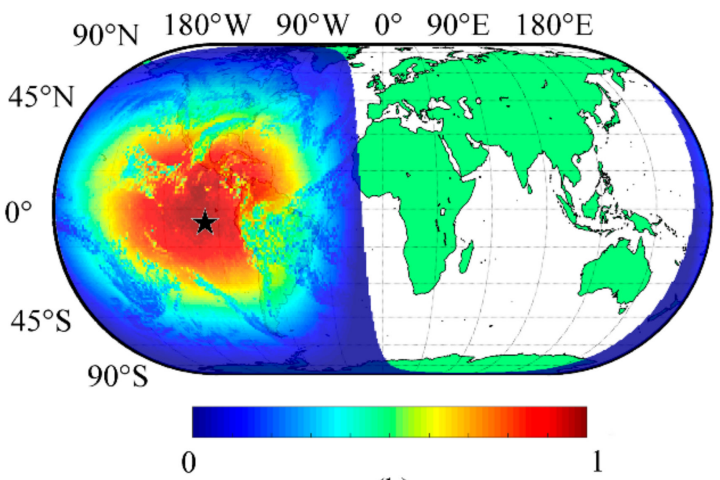

(b)

Figure 7. Distribution of (a) outgoing long-wave radiation (OLR) derived from GEOS-5 and (b) normalized OLR contribution of the elements in the observational scope observed from a Moon-based platform at 0:00 UTC on 2 January 2020.

Using Equation (19), it is clear that integral measurements can be treated as the sum of the Hadamard product of the OLR data together with the anisotropic and geometric factors. The geometric factor determines the observation geometry of the Moon-based OLR measurements and, for these type of integral measurements, it is necessary to investigate the effect of geometric factors on Moon-based OLR measurements. Firstly, we present the 
distribution of the geometric factor in the observational scope to show the distribution characteristics and compare four specific observation times during one orbital period and, then we present the effects on Moon-based OLR measurements (Figure 8). To better understand the contrast in magnitude, we normalized the geometric factors of one orbital period. From our result, it is evident that the geometric factor of the observed points reaches a maximum near the nadir point, while the value is lower near the limb of the observational scope. This is due to the effects of the Earth's curvature. Thus, for an almost hemispheric observational scope, the viewing zenith angle is the most important factor affecting the distribution of the geometric factor. The cosine of the viewing zenith angle approaches 1 near the nadir point, while the value decreases towards 0 when located at the limb of the observational scope. Although other factors, such as the angle between the pointing vector and the light ray, can also affect the results, the effects are too small to cause significant changes in distribution. By comparing the distribution at perigee and apogee (Figure $8 \mathrm{a}, \mathrm{b}$ ), we found that changes in observation distance affect its maximum value, and further result in differences with the changing observational scope. For the maximum inclination (Figure 8c,d), a large inclination did not affect the area of the observational scope, and only the distribution of the geometric factor near the polar regions changed slightly in the observational scope because of the smaller area of the element.

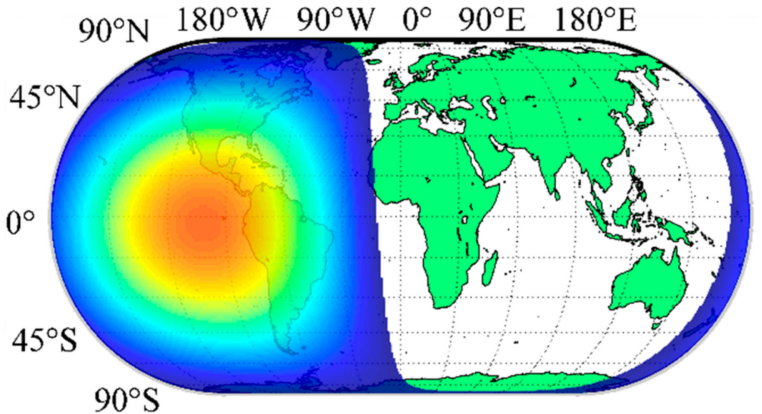

(a)

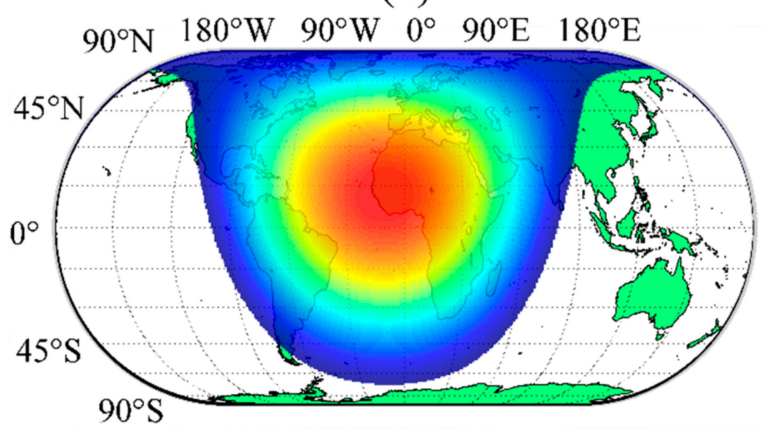

(c)

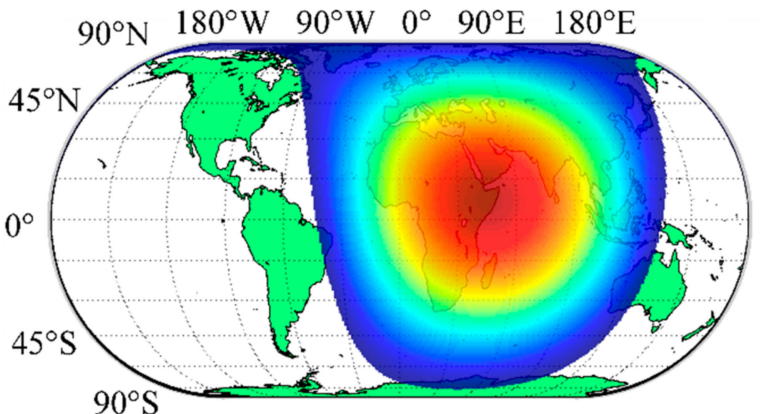

(b)

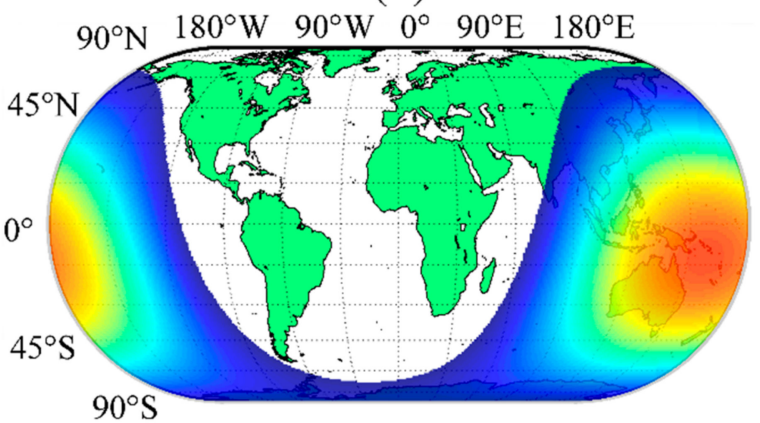

(d)

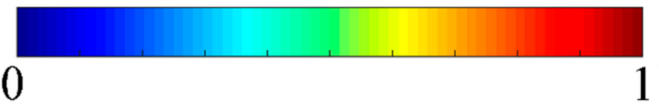

Figure 8. Distribution of the normalized geometric factor with the Moon at (a) perigee, (b) apogee, (c) maximum inclination above the Earth equator plane, and (d) maximum inclination below the Earth equator plane.

The geometric factors of all the elements in the observational scope were integrated to reveal the effects of the integrated geometric factor on the Moon-based OLR measurements. Figure 9 compares the variations in the integrated geometric factor and Moon-based OLR measurements during one orbital period. As described above, the integrated geometric factor is subjected to the observation distance. Because variations in observation distance are continuous, the variation in the geometric factor presents a smooth curve. In contrast, the general trend of the variation in the Moon-based OLR measurement is similar to that of the integrated geometric factor. However, it has the obvious characteristics of daily cycles. 
This is because of the effects of the Earth's rotation. The Earth's rotation does not change the observation distance significantly, but the scene in the observational scope. Thus, daily cycles are found in the variations in Moon-based OLR measurements. In general, the integrated geometric factor can describe the trend of Moon-based OLR measurements, especially the variation caused by changes in distance.

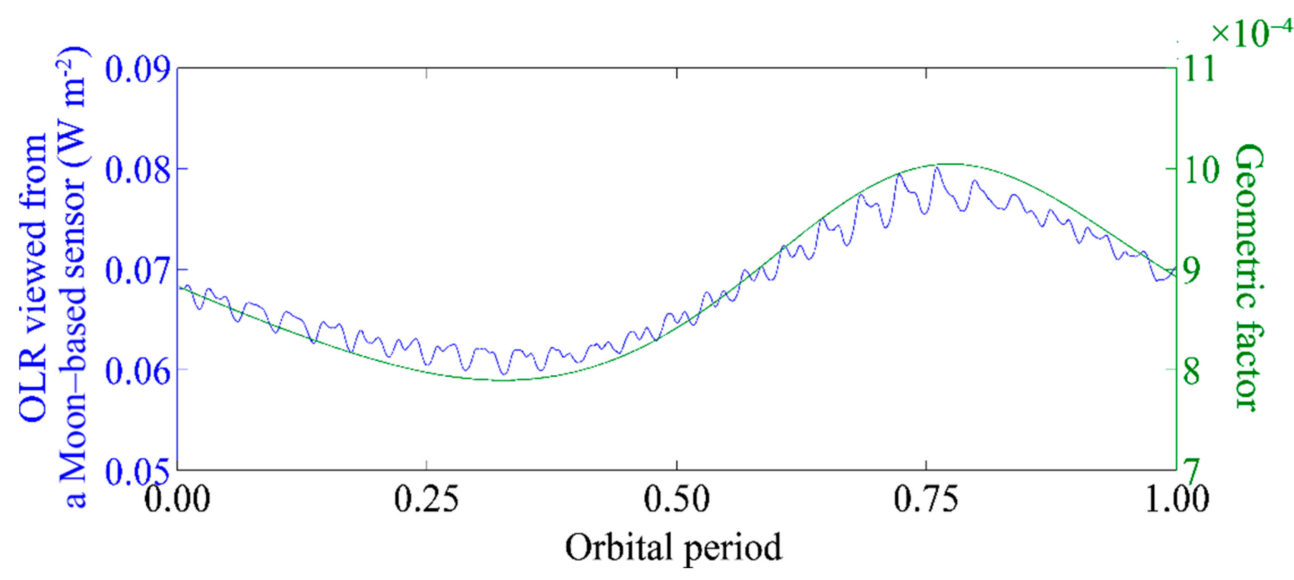

Figure 9. Comparisons of Moon-based outgoing long-wave radiation (OLR) measurements (blue curve) and the integrated geometric factor (green curve) during one orbital period.

\subsection{Comparisons of the OLR Measurements at Different Positions on the Lunar Surface}

In contrast to other space borne platforms, the Moon is a celestial body with vast locations for the installation of sensors. Installing sensors at different positions on the lunar surface will result different measurements as the position in which the sensor is installed determines the position of the nadir point on Earth. In addition, the distance between the Moon-based sensor and the Earth will be slightly different depending on the position of the sensor on the lunar surface. Assuming that the sensor's pointing vector always points through the Earth's barycenter, the composite distributions of OLR measurements at different positions on the lunar surface can be compared (Figure 10).
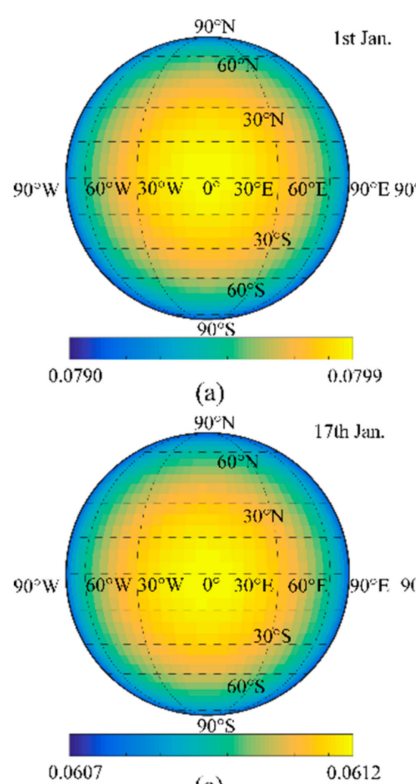

(e)
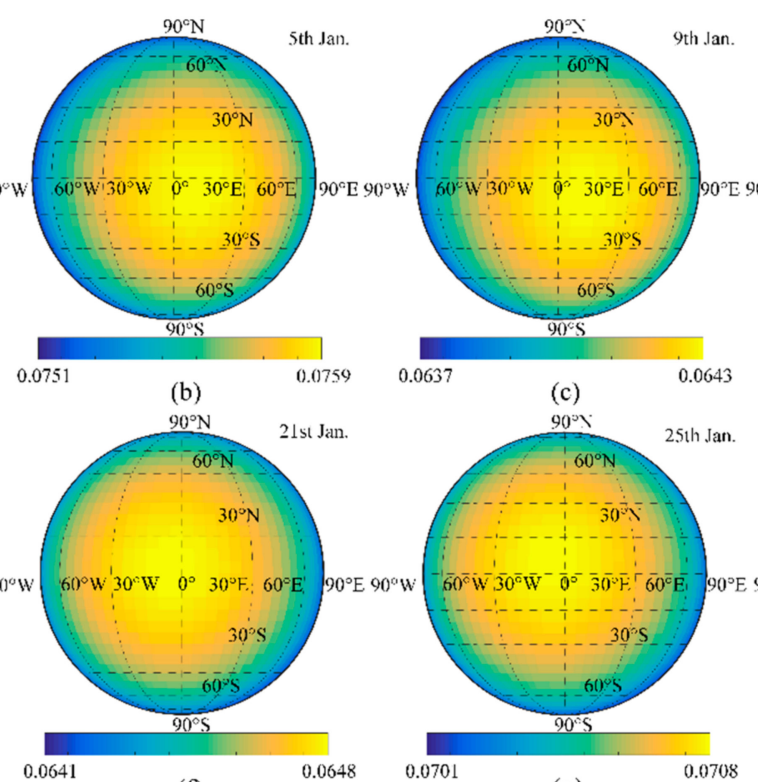

(f)

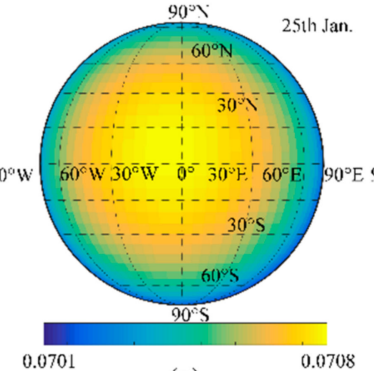

(g)

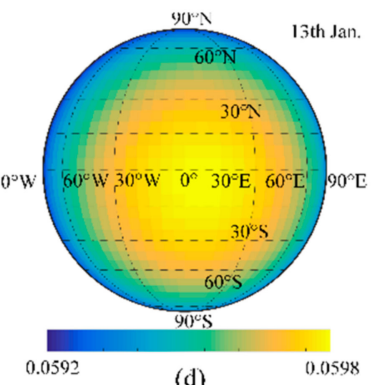

(d)

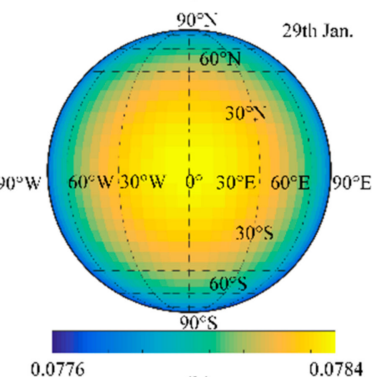

(h)

Figure 10. Distribution of Moon-based OLR measurements $\left(\mathrm{W} \mathrm{m}^{-2}\right)$ on the near-side of the Moon during one orbital period; $(\mathbf{a}-\mathbf{h})$ represent the distribution for January 2020, with an interval of four days. 
As expected, all the subfigures show the distribution of large values near the center of the lunar disk and small values at the limb of the lunar disk. This indicates that regions most sensitive to emitted OLR in the observational scope are located near the center of the lunar disk, because of the observation distance between the sensor and the Earth. Therefore, locations farther away from the Earth will results in lower measurements. In the regions between $60^{\circ} \mathrm{W}$ and $60^{\circ} \mathrm{E}$ longitude and between $60^{\circ} \mathrm{S}$ and $60^{\circ} \mathrm{N}$ latitude, differences in OLR measurements from different locations are small, no more than $2 \times 10^{-4} \mathrm{~W} \mathrm{~m}^{-2}$, because the effects of the lunar curvature on the observation distance are not very significant. For the remaining regions, differences in Moon-based OLR measurements were approximately $9 \times 10^{-4} \mathrm{~W} \mathrm{~m}^{-2}$. By comparing these subfigures, we found the distribution of these measurements to be centered at the projection of the Earth's barycenter from the lunar surface. Because the maximum movement of the projection at latitude is $6^{\circ}$, the distribution moves slightly over time. When the projection moves to the maximum latitude, the inclination reaches a maximum simultaneously, therefore, indicating that effect of inclination on the distribution of measurements from the lunar surface.

The integrated geometric factor can describe the trend of the OLR measurements (Figure 11); thus, we further show the distribution of the integrated geometric factor during one orbital period in Figure 10. As the comparison of OLR measurements and related integrated geometric factors results in similar patterns, we can conclude that the distribution of OLR measurements is sensitive to the integrated geometric factor. Given the averaged emitted OLR in the observational scope, and combining it with the respective integrated geometric factor, the difference in the measured OLR can be estimated. The calculations can be expressed as the product of the integrated geometric factor (unit: sr) and the average emitted OLR in the observational scope (unit: $\mathrm{W} \mathrm{m}^{-2} \mathrm{sr}^{-1}$ ). Assuming an averaged emitted OLR in the observational scope of $250 \mathrm{~W} \mathrm{~m}^{-2}$ during one orbital period, the maximum difference is approximately $9 \times 10^{-4} \mathrm{~W} \mathrm{~m}^{-2}$, corresponding to the differences in the calculated values. Further, to evaluate the sensitivity of the emitted OLR to the increment, the maximum difference of $1 \mathrm{~W} \mathrm{~m}^{-2}$ increment shown in the measurement at different positions is only $10^{-6} \mathrm{~W} \mathrm{~m}^{-2}$.
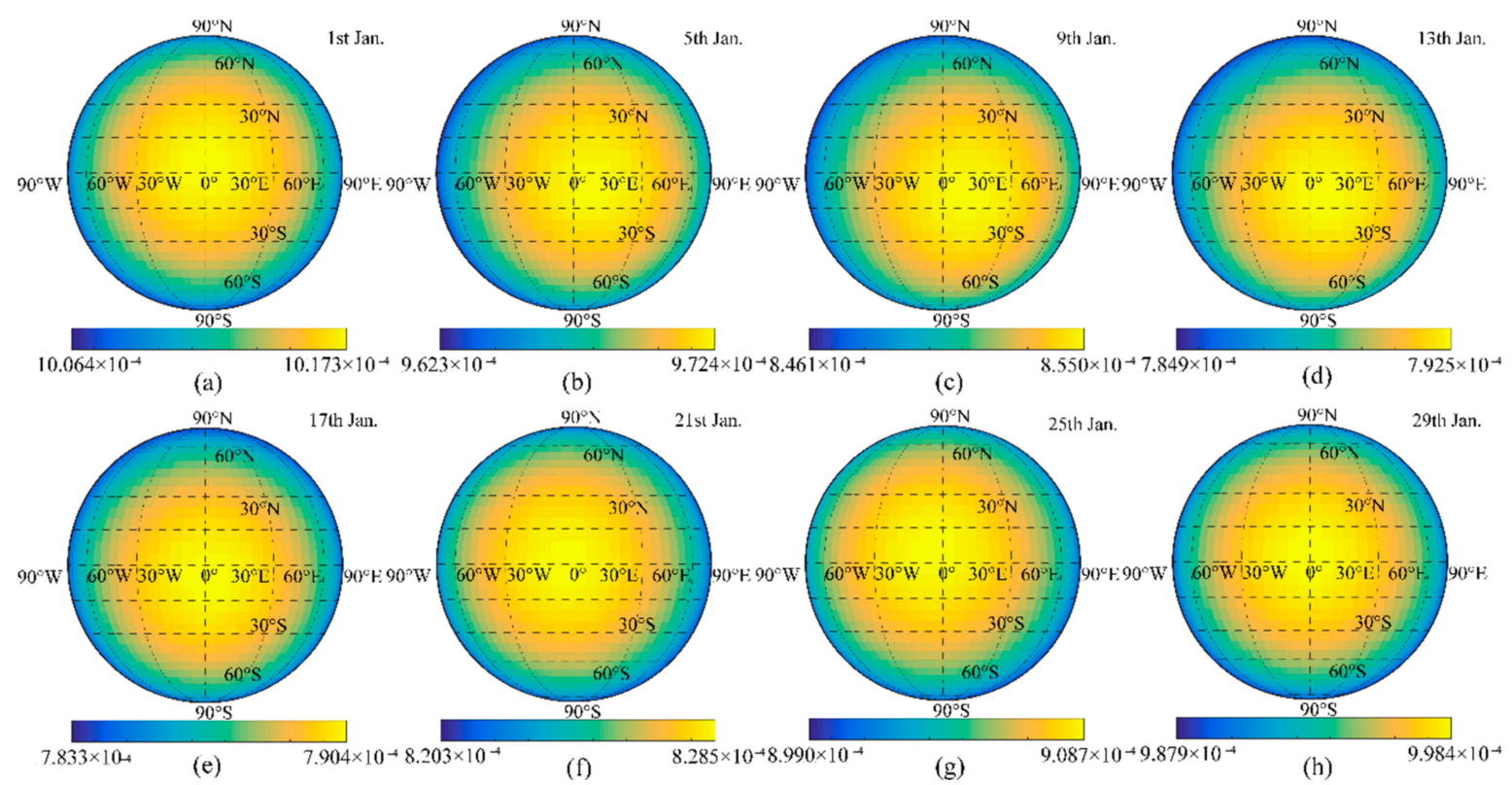

Figure 11. Distribution of the geometric factor (sr) on the near-side of the Moon during one orbital period; (a-h) represent the distribution for January 2020, with a four-day interval.

To summarize, the maximum difference in Moon-based OLR measurements can be estimated by calculating the difference between integrated geometric factors. To compare the OLR measured from different positions on the lunar surface, the maximum differences 
during one orbital period were in the order of $10^{-4} \mathrm{~W} \mathrm{~m}^{-2}$. Regarding sensitivity to the increment, the maximum difference was only approximately $10^{-6} \mathrm{~W} \mathrm{~m}^{-2}$.

\section{Discussions}

As can be inferred from our results, Moon-based OLR measurements differ to those of existing Earth observation platforms. Notably, the use of Moon-based sensors allows the Earth to be observed as a single pixel. Within this context, our study focused on global coverage and OLR measurements estimation based on the Moon-based Earth observation geometry. This included the development of a theoretical model for estimating observational scope and the OLR recorded from a Moon-based sensor. Furthermore, we discuss the potential of the Moon-based OLR measurements from a global coverage and magnitude perspective. In addition, we analyze the characteristics of Moon-based OLR measurements from different sensor locations on the lunar surface to inform the selection of an appropriate site.

The developed model includes novel characteristics, which are beneficial for the estimation of Moon-based OLR measurements. Specifically, the geometric factor matrix is separated from Equation (17) to investigate the effects of observation geometry. Notably, the calculated global mean OLR, forms the basis of subsequent analyses and equates to the value of OLR emitted from the observational scope, rather than the value observed by the sensor. With the aid of a geometric factor matrix, the OLR emitted from the observational scope could be calculated. In addition, the effects of the observation geometry on the measurements could be investigated by the comparison of geometric factors. Although in previous studies the observational scope was calculated using criterions [61], this method has significant constraints in the estimation of the OLR measurements as criterions need to be used repeatedly. Furthermore, the related calculations are very complicated, as the OLR data are given in the form of latitude-longitude grids, rather than in Cartesian coordinates. Rather, the observational scope should be expressed as a function of the nadir point and the altitude of a Moon-based platform. Thus, in our study, by expressing the elevation angle and setting constraints, the observational scope was calculated as a function of the nadir point and altitude of the Moon-based sensor. By using Equation (15), the effects of the nadir point, altitude, and height of the TOA from the observational scope could be easily analyzed. Therefore, the calculations proposed in this study improve the descriptive capability of the observational scope.

Since the orbit of the Moon is a natural orbit, a Moon-based platform has the particular observations that are distinguished from other artificial satellites. The first is its high orbital altitude is far away from the Earth, which is 10 times that of geostationary orbit. By using this kind of platform, continuous Earth observation capabilities over great temporal and spatial scales can be provided. Such a huge observation distance is benefit to observe the Earth as a single point. In contrast to the satellite on the Sun-Earth L1, which can only observe the sunlit portion of the Earth, the solar angle of the Moon-based Earth observations is not fixed. Another feature is the varied lunar inclination relative to the Earth's equator. The varied lunar inclination relative to the Earth's equator allows the completely observations to the whole regions on Earth, and of course riches the diversity of observation angles for regions on Earth compared to the cases of the fixed inclination. The low Earth orbit, geosynchronous orbit, inclined geosynchronous orbit and even other high Earth orbits are all have fixed orbit inclination. That means, there will be more limitations of the observation angular sampling than the case of the Moon-based Earth observations.

A Moon-based platform will have a temporal coherence and spatial continuity hemispheric-scale view of the Earth above the lunar surface. As the Earth rotates, a Moon-based platform can also achieve combinations of varied and continuous observation angles and solar angles. These attributes result in Earth observations that are not available from existing Earth observation platforms. Regarding global samplings, a Moon-based platform could attain a minimum of 1700 samplings of the entire Earth during one orbital period at a temporal resolution of $10 \mathrm{~min}$. In addition, the distribution of the samplings 
would be relatively uniform, with a maximum difference of the samplings of approximately 200 times (Figure 4). Therefore, a Moon-based platform has the capability to guarantee global coverage, including the Polar Regions. Furthermore, the range in magnitude of the OLR measured from the lunar surface, 0.058 to $0.083 \mathrm{~W} \mathrm{~m}^{-2}$ (Figure 6), is sufficient for observations with current CERES sensors [62]. In addition, Moon-based OLR measurements can reflect the characteristics of the OLR emitted from the observational scope. Through the transformation between measured and emitted values, the emitted OLR at the Earth Moon-facing hemisphere can be recorded, and the global mean OLR can be estimated by integrating the data over a period of time estimated.

Site selection is the primary issue in the follow-up implementation of a Moon-based platform. The site selection of existing Earth observation sensors, such as the far-ultraviolet camera in the Apollo 16 mission and the extreme ultraviolet camera (EUVC) from the CE-3 mission have the primary goal investigating possible landing areas, rather than the requirements of Earth observations. The Earth observation sensors of these missions are similar to experimental set-ups. However, for the site selection of Earth observations, factors concerning Earth observation geometry become more significant. Within this field, many researchers have compared the Earth observation geometry of sensors installed at different positions on the lunar surface. The majority of the previous studies have indicated that sensors installed on the mid-low latitude region of the Moon will achieve better observation results by avoiding blocking the line of sight $[63,64]$. The lunar surface is divided into four regions based on different sight conditions between the observed points on Earth and Moon-based platform. Full observation region, which is between $80^{\circ} \mathrm{W}$ and $80^{\circ} \mathrm{E}$ longitude and between $81^{\circ} \mathrm{S}$ and $81^{\circ} \mathrm{N}$ latitude, is proposed to be idea places to install sensors. Our results also support this view (Figures 9 and 10). In the region between $60^{\circ} \mathrm{W}$ and $60^{\circ} \mathrm{E}$ longitude and $60^{\circ} \mathrm{S}$ and $60^{\circ} \mathrm{N}$ latitude, the measured OLR was higher than that from high latitude regions, and the maximum difference was approximately $9 \times 10^{-4} \mathrm{~W}$ $\mathrm{m}^{-2}$. However, sight conditions are not the only constraints to the development of a Moonbased sensor. For the consideration of the geolocation error caused by exterior orientation elements, it is found that high-latitude regions have less import on the platform's position error [65]. Additionally, solar invasion effects need to be considered. It is suggested that mid-high latitude regions within the full observation region will result in less solar invasion effects [66]. After combining all these factors, we suggested that, although sensors installed at mid-high latitudes will have a smaller measured OLR, the reduction is acceptable, and the places at the limb of the regions between $60^{\circ} \mathrm{W}$ and $60^{\circ} \mathrm{E}$ longitude and $60^{\circ} \mathrm{S}$ and $60^{\circ} \mathrm{N}$ latitude offer ideal locations for the installation of Earth observation sensors.

\section{Conclusions}

In this study, we investigated the potential of Moon-based OLR measurements, from the perspective of observation geometry, to estimate the global mean OLR. For a Moonbased platform, the Earth can be observed as a single point, which could reduce spatiotemporal sampling errors. Furthermore, the varied inclination of the orbit of the Moon increases angular observation samplings across different locations on Earth. To this end, we developed a theoretical model by integrating all the received OLR of the elements in the observational scope. Based on this model, we analyzed global sampling distribution of Moon-based Earth observations during one orbital period. Furthermore, we investigated the effects of observation geometry by separating the geometric factors from the measurement calculations. In addition, the effects of sensors located at different positions on the lunar surface were also compared.

Our results indicate that global sampling distributions of Moon-based Earth observations were related to the latitudinal range of the nadir point during one orbital period. A Moon-based platform could achieve relatively uniform global sampling within one orbital period. From the magnitude of the Moon-based OLR measurements, the range lies between 0.058 and $0.083 \mathrm{~W} \mathrm{~m}^{-2}$, which reflects the characteristics of the OLR emitted from the observational scope. We further separated the geometric factors from the OLR measurement 
calculations to identify the effects of observation geometry on measurements. Combined with the anisotropic factor, the Earth-Moon distance together with the anisotropy of the Earth's scene within the observational scope represent the primary factors that influence Moon-based OLR measurements. Owing to the observation distance of the position near the center of the lunar disk being smaller than that at the limb of the lunar disk, higher measurement distribution values were recorded near the center of the lunar disk. By calculating the difference in the distribution of the measurements, the maximum difference was recorded as approximately $9 \times 10^{-4} \mathrm{~W} \mathrm{~m}^{-2}$. Although the installation of sensors on the mid-low latitude regions will have a larger response to the OLR, we suggest that these locations would not significantly enhance the capability of the observation performance. The reduction in the response to the OLR in mid-high latitude regions is acceptable. By estimating the Moon-based Earth observation geometry and its OLR measurements, we suggest that a Moon-based platform has the potential to record the necessary data to estimate the global mean OLR.

Author Contributions: Conceptualization, H.Y., H.G., G.L. and L.Z.; Methodology, H.Y., G.L., J.P. and L.Z.; Supervision, H.G.; Validation, H.Y., G.L. and J.P.; Visualization, H.Y.; Writing-Original Draft, H.Y., G.L. and J.P.; Writing-Review and Editing, H.Y., H.G., G.L., J.P. and Y.Z. All authors have read and agreed to the published version of the manuscript.

Funding: This research was funded by the National Key Research and Development Program of China, (No. 2020YFE0202100), Qian Xuesen Youth Innovation Fund of China Aerospace Science and Technology Group (No. Y-KC-JT-QXS-014), and the Open Research Fund of Key Laboratory of Digital Earth Science, Chinese Academy of Sciences, grant 2019LDE001.

Institutional Review Board Statement: Not applicable.

Informed Consent Statement: Not applicable.

Data Availability Statement: Not applicable.

Conflicts of Interest: The authors declare no conflict of interest.

\section{References}

1. Hansen, J.; Sato, M.; Kharecha, P.; Schuckmann, K.V. Earth's energy imbalance and implications. Atmos. Chem. Phys. 2011, 11, 13421-13449. [CrossRef]

2. Gristey, J.J.; Chiu, J.C.; Gurney, R.J.; Morcrette, C.J.; Hill, P.G.; Russell, J.E.; Brindley, H.E. Insights into the diurnal cycle of global Earth outgoing radiation using a numerical weather prediction model. Atmos. Chem. Phys. 2018, 18, 5129-5145. [CrossRef]

3. Dewitte, S.; Clerbaux, N. Decadal Changes of Earth's Outgoing Longwave Radiation. Remote Sens. 2018, 10, 1539. [CrossRef]

4. Golovko, V.A. The Earth Radiation Budget, 20 Years Later (1985-2005); Springer: Berlin/Heidelberg, Germany, 2009 ; pp. 37-61.

5. Bess, T.D.; Smith, G.L.; Charlock, T.P. A ten-year monthly data set of outgoing longwave radiation from Nimbus-6 and Nimbus-7 satellites. Bull. Am. Meteorol. Soc. 1989, 70, 480-489. [CrossRef]

6. Gruber, A.; Jacobowitz, H. The longwave radiation estimated from NOAA polar orbiting satellites: An update and comparison with Nimbus-7 ERB results. Adv. Space Res. 1985, 5, 111-120. [CrossRef]

7. Hatzianastassiou, N.; Croke, B.; Kortsalioudakis, N.; Vardavas, I.; Koutoulaki, K. A model for the longwave radiation budget of the Northern hemisphere: Comparison with Earth Radiation Budget Experiment data. J. Geophys. Res. Atmos. 1999, 104, 9489-9500. [CrossRef]

8. Hakuba, M.Z.; Stephens, G.L.; Christophe, B.; Nash, A.E.; Foulon, B.; Bettadpur, S.V.; Tapley, B.D.; Webb, F.H. Earth's Energy Imbalance Measured from Space. IEEE T. Geosci. Remote Sens. 2018, 1-14. [CrossRef]

9. Vardavas, I.M.; Koutoulaki, K. A model for the solar radiation budget of the northern hemisphere: Comparison with Earth Radiation Budget Experiment data. J. Geophys. Res. 1995, 100, 7303-7314. [CrossRef]

10. Wielicki, B.A.; Barkstrom, B.R.; Harrison, E.F.; Lee, R.B.; Smith, G.L.; Cooper, J.E. Clouds and the Earth's Radiant Energy System (CERES): An Earth Observing System Experiment. Bull. Am. Meteorol. Soc. 1998, 36, 1127-1141. [CrossRef]

11. Jacobowitz, H.; Soule, H.V.; Kyle, H.L.; House, F.B. The Earth Radiation Budget (Erb) Experiment-An Overview. J. Geophys. Res. Atmos. 1984, 89, 5021-5038. [CrossRef]

12. House, F.B.; Gruber, A.; Hunt, G.E.; Mecherikunnel, A.T. History of satellite missions and measurements of the Earth Radiation Budget (1957-1984). Rev. Geophys. 1986, 24, 357-377. [CrossRef]

13. Shrestha, A.K.; Kato, S.; Wong, T.; Stackhouse, P.W.; Rose, F.; Miller, W.F.; Bush, K.; Rutan, D.A.; Minnis, P.; Doelling, D. Spectral unfiltering of ERBE WFOV nonscanner shortwave observations and revisiting its radiation dataset from 1985 to 1998 . In Proceedings of the International Radiation Symposium, Auckland, New Zealand, 16-22 April 2016; pp. 379-390. 
14. Harries, J.E.; Russell, J.E.; Hanafin, J.A.; Brindley, H.; Futyan, J.; Rufus, J.; Kellock, S.; Matthews, G.; Wrigley, R.; Last, A. The Geostationary Earth Radiation Budget Project. Bull. Am. Meteorol. Soc. 2005, 86, 945-960. [CrossRef]

15. Kandel, R.S.; Viollier, M.; Raberanto, P.; Duvel, J.P.; Pakhomov, L.A.; Golovko, V.A.; Trishchenko, A.P.; Mueller, J.; Raschke, E.; Stuhlmann, R. The ScaRaB Earth Radiation Budget Dataset. Bull. Am. Meteorol. Soc. 1998, 79, 765-783. [CrossRef]

16. Qiu, H.; Hu, L.; Zhang, Y.; Lu, D.; Qi, J. Absolute Radiometric Calibration of Earth Radiation Measurement on FY-3B and Its Comparison With CERES/Aqua Data. IEEE T. Geosci. Remote Sens. 2012, 50, 4965-4974. [CrossRef]

17. Burt, J.; Smith, B. Deep Space Climate Observatory: The DSCOVR Mission. In Proceedings of the Aerospace Conference, Big Sky, MT, USA, 3-10 March 2012.

18. Valero, F.P.J. Keeping the DSCOVR mission alive. Science 2006, 311, 775c-776c. [CrossRef]

19. Su, W.; Minnis, P.; Liang, L.; Khlopenkov, K.; Thieman, M.M.; Yu, Y.; Smith, A.; Lorentz, S.; Feldman, D.; Valero, F.P.J. Determining the daytime Earth radiative flux from National Institute of Standards and Technology Advanced Radiometer (NISTAR) measurements. Atmos. Meas. Tech. 2020, 13, 429-443. [CrossRef]

20. Zhu, P.; Ruymbeke, M.V.; Karatekin, Ö.; Noël, J.P.; Irbah, A. A high dynamic radiation measurement instrument: The Bolometric Oscillation Sensor (BOS). Geosci. Instrum. Methods Data Syst. Discuss. 2015, 4, 89-98. [CrossRef]

21. Zhu, P.; Wild, M.; Ruymbeke, M.V.; Thuillier, G.; Meftah, M.; Karatekin, O. Interannual variation of global net radiation flux as measured from space. J. Geophys. Res. Atmos. 2016, 121, 6877-6891. [CrossRef]

22. Swartz, W.H.; Lorentz, S.R.; Papadakis, S.J.; Huang, P.M.; Anderson, D.E. RAVAN: CubeSat Demonstration for Multi-Point Earth Radiation Budget Measurements. Remote Sens. 2019, 11, 796. [CrossRef]

23. Loeb, N.G.; Wielicki, B.A.; Doelling, D.R.; Smith, G.L.; Keyes, D.F.; Kato, S.; Manalo-Smith, N.; Wong, T. Toward Optimal Closure of the Earth's Top-of-Atmosphere Radiation Budget. J. Clim. 2009, 22, 748-766. [CrossRef]

24. Loeb, N.G.; Doelling, D.R.; Wang, H.; Su, W.; Nguyen, C.; Corbett, J.G.; Liang, L.; Mitrescu, C.; Rose, F.G.; Kato, S. Clouds and the Earth'S Radiant Energy System (CERES) Energy Balanced and Filled (EBAF) top-of-atmosphere (TOA) edition-4.0 data product. J. Clim. 2017, 31, 895-918. [CrossRef]

25. Li, C.; Wang, C.; Wei, Y.; Lin, Y. China's present and future lunar exploration program. Science 2019, 365, 238-239. [CrossRef]

26. Zielinski, S. NASA's plans for Moon base. Eos Trans. Am. Geophys. Union 2013, 87, 594. [CrossRef]

27. Duke, M.B.; Mendell, W.W. Scientific investigations at a lunar base. Acta Astronaut. 1988, 17, 675-690. [CrossRef]

28. Guo, H.; Liu, G.; Ding, Y. Moon-based Earth Observation: Scientific Concept and Potential Applications. Int. J. Digit. Earth 2017, 11, 546-557. [CrossRef]

29. Guo, H.; Ren, Y.; Liu, G.; Ye, H. The angular characteristics of Moon-based Earth observations. Int. J. Digit. Earth 2019, 13, 339-354. [CrossRef]

30. Cremers, C.J.; Birkebak, R.C.; White, J.E. Lunar surface temperatures from Apollo 12. Moon 1972, 3, 346-351. [CrossRef]

31. Schwadron, N.A.; Baker, T.; Blake, B.; Case, A.W.; Cooper, J.F.; Golightly, M.; Jordan, A.; Joyce, C.; Kasper, J.; Kozarev, K. Lunar radiation environment and space weathering from the Cosmic Ray Telescope for the Effects of Radiation (CRaTER). J. Geophys. Res. Planets 2012, 117, E00H13. [CrossRef]

32. Pilipenko, V.; Yagova, N.; Romanova, N.; Allen, J. Statistical relationships between satellite anomalies at geostationary orbit and high-energy particles. Adv. Space Res. 2006, 37, 1192-1205. [CrossRef]

33. Durante, M.; Cucinotta, F.A. Physical basis of radiation protection in space travel. Rev. Mod. Phys. 2011, 83, 1245. [CrossRef]

34. Johnson, J.R.; Lucey, P.G.; Stone, T.C. Visible/Near-Infrared Remote Sensing of Earth from the Moon, NASA Advisory Council Workshop on Science Associated with the Lunar Exploration Architecture White Papers. 2007.

35. Hamill, P. Atmospheric observations from the moon: A lunar earth-observatory. NASA advisory council workshop on science associated with the lunar exploration architecture white papers. 2007.

36. Guo, H.D.; Liu, G.; Ding, Y.X.; Zou, Y.L.; Huang, S.P.; Jiang, L.M.; Jia, G.S.; Lv, M.Y.; Ren, Y.Z.; Ruan, Z.X.; et al. Moon-Based Earth Observation for Large Scale Geoscience Phenomena. In Proceedings of the International Geoscience and Remote Sensing Symposium, Beijing, China, 10-15 July 2016; pp. 3705-3707.

37. Hamill, P. Atmospheric Observations from the Moon: A Lunar Earth-Observatory. Int. Geosci. Remote Se. 2016, 3719-3722. [CrossRef]

38. Renga, A.; Moccia, A. Moon-based Synthetic Aperture Radar: Review and challenges. In Proceedings of the IEEE International Geoscience and Remote Sensing Symposium, Beijing, China, 10-15 July 2016.

39. He, F.; Zhang, X.; Chen, B.; Fok, M.; Nakano, S. Determination of the Earth's Plasmapause Location from the CE-3 EUVC Images. J. Geophys. Res. 2016, 121, 296-304. [CrossRef]

40. Carruthers, G.R.; Page, T. Apollo 16 far-ultraviolet camera/spectrograph-Earth observations. Science 1972, $177,788-791$. [CrossRef]

41. Zhang, L.; Guo, H.; Jiao, H.; Liu, G.; Shen, G.; Wu, W. A polar coordinate system based on a projection surface for moon-based earth observation images. Adv. Space Res. 2019, 64, 2209-2220. [CrossRef]

42. Ye, H.; Zheng, W.; Guo, H.; Liu, G. Effects of Temporal Sampling Interval on the Moon-based Earth Observation Geometry. IEEE J. Stars 2020. [CrossRef]

43. Xu, Z.; Chen, K.-S. Effects of the Earth's Curvature and Lunar Revolution on the Imaging Performance of the Moon-Based Synthetic Aperture Radar. IEEE Trans. Geosci. Remote Sens. 2019, 57, 5868-5882. [CrossRef] 
44. Ding, Y.; Guo, H.; Liu, G.; Han, C.; Lv, M. Constructing a High-Accuracy Geometric Model for Moon-Based Earth Observation. Remote Sens. 2019, 11, 2611. [CrossRef]

45. Nie, C.; Liao, J.; Shen, G.; Duan, W. Simulation of the land surface temperature from moon-based Earth observations. Adv. Space Res. 2019, 63, 826-839. [CrossRef]

46. Sui, Y.; Guo, H.; Liu, G.; Ren, Y. Analysis of Long-Term Moon-Based Observation Characteristics for Arctic and Antarctic. Remote Sens. 2019, 11, 2805. [CrossRef]

47. Ren, Y.; Guo, H.; Liu, G.; Ye, H. Simulation Study of Geometric Characteristics and Coverage for Moon-Based Earth Observation in the Electro-Optical Region. IEEE J. Sel. Top. Appl. Earth Obs. Remote Sens. 2017, 10, 2431-2440. [CrossRef]

48. Ye, H.; Guo, H.; Liu, G.; Shen, G.; Xu, Z. Simulation Study of the Earth Radiation Budget Experiment on the Moon-Based Earth Observation Platform. In Proceedings of the IEEE International Geoscience and Remote Sensing Symposium, Valencia, Spain, 22-27 July 2018.

49. Wu, K.; Ji, C.; Luo, L.; Wang, X. Simulation Study of Moon-Based InSAR Observation for Solid Earth Tides. Remote Sens. 2020, 12, 123. [CrossRef]

50. Song, Y.; Wang, X.; Bi, S.; Wu, J.; Huang, S. Effects of solar radiation, terrestrial radiation and lunar interior heat flow on surface temperature at the nearside of the Moon: Based on numerical calculation and data analysis. Adv. Space Res. 2017, 60, 938-947. [CrossRef]

51. Ye, H.; Guo, H.; Liu, G.; Guo, Q.; Zhang, L.; Huang, J. Temporal sampling error analysis of the Earth's outgoing radiation from a Moon-based platform. Int. J. Remote Sens. 2019, 40, 6975-6992. [CrossRef]

52. Duan, W.; Huang, S.; Nie, C. Entrance Pupil Irradiance Estimating Model for a Moon-Based Earth Radiation Observatory Instrument. Remote Sens. 2019, 11, 583. [CrossRef]

53. Loeb, N.G.; Kato, S.; Wielicki, B.A. Defining Top-of-the-Atmosphere Flux Reference Level for Earth Radiation Budget Studies. J. Clim. 2002, 15, 3301-3309. [CrossRef]

54. Loeb, N.G.; Manalosmith, N.; Kato, S.; Miller, W.F.; Gupta, S.K.; Minnis, P.; Wielicki, B.A. Angular Distribution Models for Top-of-Atmosphere Radiative Flux Estimation from the Clouds and the Earth's Radiant Energy System Instrument on the Tropical Rainfall Measuring Mission Satellite. Part I: Methodology. J. Appl. Meteorol. 2003, 42, 240-265. [CrossRef]

55. Loeb, N.G.; Loukachine, K.; Manalosmith, N.; Wielicki, B.A.; Young, D.F. Angular Distribution Models for Top-of-Atmosphere Radiative Flux Estimation from the Clouds and the Earth's Radiant Energy System Instrument on the Tropical Rainfall Measuring Mission Satellite. Part II: Validation. J. Appl. Meteorol. 2003, 42, 1748-1769. [CrossRef]

56. Suttles, J.T.; Green, R.N.; Smith, G.L.; Wielicki, B.A.; Walker, I.J.; Taylor, V.R.; Stowe, L.L. Angular Radiation Models for EarthAtmosphere System. Volume 2: Longwave Radiation; NASA: Washington, DC, USA, 1989.

57. Comer, R.E.; Slingo, A.; Allan, R.P. Observations of the diurnal cycle of outgoing longwave radiation from the Geostationary Earth Radiation Budget instrument. Geophys. Res. Lett. 2007, 34. [CrossRef]

58. Smith, G.L.; Rutan, D.A. The Diurnal Cycle of Outgoing Longwave Radiation from Earth Radiation Budget Experiment Measurements. J. Atmos. Sci. 2003, 60, 1529-1542. [CrossRef]

59. Kiehl, J.T.; Trenberth, K.E. Earth's Annual Global Mean Energy Budget. Bull. Am. Meteorol. Soc. 1997, 78, 197-208. [CrossRef]

60. Jordan, N.S.; Hoff, R.M.; Bacmeister, J.T. Validation of Goddard Earth Observing System-version 5 MERRA planetary boundary layer heights using CALIPSO. J. Geophys. Res. Atmos. 2010, 115. [CrossRef]

61. Huang, J.; Guo, H.; Liu, G.; Shen, G.; Ye, H.; Deng, Y.; Dong, R. Spatio-Temporal Characteristics for Moon-Based Earth Observations. Remote Sens. 2020, 12, 2848. [CrossRef]

62. CERES Algorithm Theoretical Basis Document. Available online: https://ceres.larc.nasa.gov/documents/ATBD/pdf/r2_2 / ceres-atbd2.2-s4.4.pdf (accessed on 3 June 2021).

63. Ye, H.; Guo, H.; Liu, G.; Ren, Y. Observation duration analysis for Earth surface features from a Moon-based platform. Adv. Space Res. 2018, 62, 274-287. [CrossRef]

64. Ye, H.; Guo, H.; Liu, G.; Ren, Y. Observation scope and spatial coverage analysis for earth observation from a Moon-based platform. Int. J. Remote Sens. 2018, 39, 5809-5833. [CrossRef]

65. Ye, H.; Zheng, W.; Guo, H.; Liu, G.; Ping, J. Effects of Solar Invasion on Earth Observation Sensors at a Moon-Based Platform. Remote Sens. 2019, 11, 2775. [CrossRef]

66. Ye, H.; Guo, H.; Liu, G.; Ping, J.; Guo, Q. Impacts of Platform's Position Errors on Geolocation for a Moon-Based Sensor. IEEE Geosci. Remote Sens. Lett. 2020, 17, 112-120. [CrossRef] 